\title{
Interactive comment on "Comparison of high frequency, in-situ water quality analysers and sensors with conventional water sample collection and laboratory analyses: phosphorus and nitrogen species” by Steven J. Granger et al.
}

\author{
Anonymous Referee \#3 \\ Received and published: 19 March 2018
}

General comments: The manuscript of Granger et al. aims at comparing in-situ high frequency water quality analysers and sensors with conventional water sample collection and laboratory analyses, focusing on phosphorus and nitrogen species. Although the topic offers potential for an in deep analysis of the precision of high frequency water quality measurements the present paper offers only a very narrow view of the topic with regard to investigated compounds, range and amount of analysed data and analytical devices. The main concerns I have are as follows: Regarding NOx-N analysis only the Nitratax UV sensor is included in the study. Although the tested sensor could 
provide comparable data to the measured using samples analysed in the laboratory, this sensor is one with the lowest precision of devices currently on the market $(0.5 \mathrm{mg}$

NOx-N L-1). Other sensors have much higher precision. This fact is not discussed in the paper and may result in a misleading assessment of optical nitrate sensors. A comprehensive analysis of most important UV sensors has already been given by the USGS some years ago (https://pubs.usgs.gov/tm/01/d5/) (2013). This study is not cited in the manuscript. The abstract suggests that always a choice has to be made between high frequency measurements of low precision and low frequency measurements of high precision. This is not proofed by the results. I cannot follow this arguing because at least in case of nitrate optical high frequency measurements do not show inevitably lower precision than laboratory measurements if the sensors are accurately maintained. Studies using high frequency in situ data mostly validate the sensors with laboratory data. This is true for optical sensors, see e.g. Pellerin et al. 2015, Heffernan and Cohen 2010 as well as for Phosphax analysers (e.g. Halliday et al. 2014). Therefore a rigorous analysis of the available literature on the precision of high frequency measurement devices would likely give a comprehensive picture on the measurement uncertainties related to these analysers. This is not the case for the presented study. $A$ comprehensive analysis of already available studies and a discussion on how the given results fit into this picture is missing. The amount of data presented in the manuscript is small. Only one runoff event of each catchment has been included in the analyses. Because all samples were taken on the same dates the range of data is narrow and very similar for all three catchments. For example all SRP values of the three catchments range between $0-70 \mu \mathrm{g} \mathrm{P} \mathrm{L-1}$. Also NOx-N ranges are similar within the three different catchments during the analysed event (below $5.1 \mathrm{mg} \mathrm{N} \mathrm{L-1}$ ). This limits possible conclusions from this investigation. Furthermore a discussion on other $\mathrm{P}$ analysers, e.g. Cycle-PO4 (Wetlabs), Cohen et al. (2013), which may provide different results, is missing. It is well known that other compounds like e.g. turbidity may interfere with nitrate sensor measurements and may affect the precision of measurement. But the presented study does not include further compounds, even not in the discussion. This

Printer-friendly version

Discussion paper 
strongly limits interpretation of the results. Another important limitation of the NH4-N analysis is given by the fact that the in situ analyser has been used for data ranges which were well below the detection limit of the instrument. Therefore I cannot understand why this analysis has been carried out at all. Because of all these limitations I do not see that the manuscript offers important outcomes beyond what already is known and therefore I cannot support the publication of the manuscript in HESS.

Literature:

Brian A. Pellerin, Brian A. Bergamaschi, Bryan D. Downing, John Franco Saraceno, Jessica D. Garrett, and Lisa D. Olsen Optical Techniques for the Determination of Nitrate in Environmental Waters: Guidelines for Instrument Selection, Operation, Deployment, Maintenance, Quality Assurance, and Data Reporting, Chapter 5 of Section D, Water Quality Book 1, Collection of Water Data by Direct Measurement, Techniques and Methods 1-D5, USGS, 2013

Cohen, M. J., M. J. Kurz, J. B. Heffernan, J. B. Martin, R. L. Douglass, C. R. Foster, and R. G. Thomas. 2013. Diel phosphorus variation and the stoichiometry of ecosystem metabolism in a large spring-fed river. Ecological Monographs 83:155-176.

Heffernan, J. B.; Cohen, M. J.; Frazer, T. K.; Thomas, R. G.; Rayfield, T. J.; Gulley, J.; Martin, J. B.; Delfino, J. J.; Graham, W. D., Hydrologic and biotic influences on nitrate removal in a subtropical spring-fed river. Limnol. Oceanogr. 2010, 55, (1), 249-263.

Halliday, S., Skeffington, R., Bowes, M., Gozzard, E., Newman, J., Loewenthal, M., et al., 2014. The water quality of the River Enborne, UK: observations from highfrequency monitoring in a rural, lowland river system. Water 6, 150-180.

Pellerin, B. A., B. A. Bergamaschi, R. J. Gilliom, C. G. Crawford, J. Saraceno, C. P. Frederick, B. D. Downing, and J. C. Murphy. 2014. Mississippi River Nitrate Loads from High Frequency Sensor Measurements and Regression-Based Load Estimation. Environmental Science \& Technology 48:12612-12619

Printer-friendly version

Discussion paper 
Interactive comment on Hydrol. Earth Syst. Sci. Discuss., https://doi.org/10.5194/hess-2017684, 2018.

Interactive

comment 